\title{
Application of Optical and Other Advanced Characterization Techniques to Understand Weld Microstructures
}

\author{
S. A. David, ${ }^{*}$ S. S. Babu, ${ }^{*}$ and J. M. Vitek* \\ *M\&C Division, Oak Ridge National Laboratory, MS-6095, PO Box 2008, Oak Ridge, TN 37831
}

Microstructure characterization of both the fusion zone (FZ) and the heat- affected zone (HAZ) in a weld is critical in understanding the weldability of structural alloys, as well as correlating the microstructure to mechanical properties of these welds. Microstructures of both the FZ and HAZ are complex due to significant gradations in composition in these regions [1]. This complexity arises due to rapid heating and cooling in a given weld thermal cycle and the spatial variation of the same. This paper highlights recent results of weld microstructure characterization using different characterization techniques including optical microscopy (OM), weld simulation techniques, scanning electron microscopy (SEM), orientational imaging microscopy (OIM), transmission electron microscopy (TEM), atom probe field ion microscopy (APFIM), X-ray diffraction (XRD) and neutron diffraction (ND).

OM has been used to characterize the solidification microstructures in both single-crystal and polycrystalline alloy welds. The effect of growth crystallography and the dendrite selection process on the development of the FZ microstructures was investigated by making welds on well-oriented single crystals of Fe-15Ni-15Cr wt.\% alloys. The observed microstructure evolution was used to validate a geometry model for dendrite growth selection. This technique was also extended to PWA1480 nickel base superalloy single crystals. Optical microscopy showed the formation of different $<001>$ dendrite growth variants as well as the formation of stray grains. The formation of stray grains in the middle of the weld was attributed to the constitutional supercooling phenomena. Optical microscopy has also been used to describe the microstructure evolution in polycrystalline stainless steel welds. With OM, the duplex microstructure containing austenite $(\gamma)$ and ferrite $(\delta)$ phases have been characterized. However, traditional metallography on one section failed to delineate different ferrite morphologies. However, by orthogonal sectioning and extensive metallography of volume elements from various locations of the weld, four distinct types of ferrite morphologies have been identified, namely vermicular, lacy, acicular and globular. In addition to morphological features, it is necessary to link the solidification behavior with solute segregation within the solidification substructure in welds. For example, in $\alpha+\beta$ titanium alloy (Ti- 6 wt. $\% \mathrm{Al}$ $-1 \% \mathrm{Nb}-1 \% \mathrm{Ta}-0.8 \% \mathrm{Mo}$ ) welds, the dendritic solidification substructure was observable by $\mathrm{X}$ ray microradiography. The chemical heterogeneity associated with the solute redistribution occurring during solidification was revealed by a variation in photographic blackening.

In many cases, electron microscopy is used to evaluate the fine details of weld metal microstructure, including crystallography, morphology and composition. For example, the cracking and stray grain formation in a single-crystal nickel base superalloy was characterized with SEM and OIM [see Fig. 1]. The OIM analysis showed that the weld cracking was associated with stray grains on only the right side of the weld. The analysis showed that the single crystal nature was preserved on the left side of the weld. This interesting phenomenon is related to crystallographic orientation of the single crystal base metal with respect to the welding direction and the constitutional supercooling conditions ahead of the dendrite tip. The TEM analysis of stainless steel weld aged at $650^{\circ} \mathrm{C}$ for

The submitted manuscript has been authored by a contractor of the U.S. Government under contract No. DE-AC05-96OR22464. Accordingly, the U.S. Government retains a nonexclusive, royalty-free license to publish or reproduce the published form of this contribution, or allow others to do so, for U.S. Government purposes. 
$1000 \mathrm{~h}$ showed the presence of $\delta$-ferrite, austenite, $\mathrm{M}_{23} \mathrm{C}_{6}$, and $\sigma$ phases [see Fig. 2]. The formation of $\mathrm{M}_{23} \mathrm{C}_{6}$ carbides along the original $\delta$-ferrite - austenite boundary is related to the creep rupture properties. To understand the mechanisms of phase transformations it is often necessary to use highresolution characterization techniques including atom probe field ion microscopy (APFIM). In addition, atom probe tomography (APT), based on the APFIM principle, allows us to reconstruct the 3-D morphology of nanometer scale precipitates. The APT results showed the presence of secondary $\gamma^{\prime}$ precipitates in a $\gamma$ matrix in a sample that was cooled at $1 \mathrm{Ks}^{-1}$ from $1300{ }^{\circ} \mathrm{C}$ [see Fig. 3]. There is an impetus to characterize the dynamics weld microstructure evolution as a function of the weld thermal cycle. With the advent of high-flux neutron and synchrotron sources, it is possible to characterize the relative fractions of phases in welds during heat treatment or during weld cooling respectively. Recently, using a time-resolved X-ray diffraction technique, nonequilibrium phase selection in low-alloy steel was observed. The above examples show that through combined application of different techniques it is possible to characterize weld microstructure completely [2].

\section{References}

[1] S. A. David and T. DebRoy: Science, 257 (1992), p. 497.

[2] This research was sponsored by the Division of Materials Science and Engineering U.S.

Department of Energy, under Contract DE-AC05-00OR22725 with UT-Battelle, LLC.
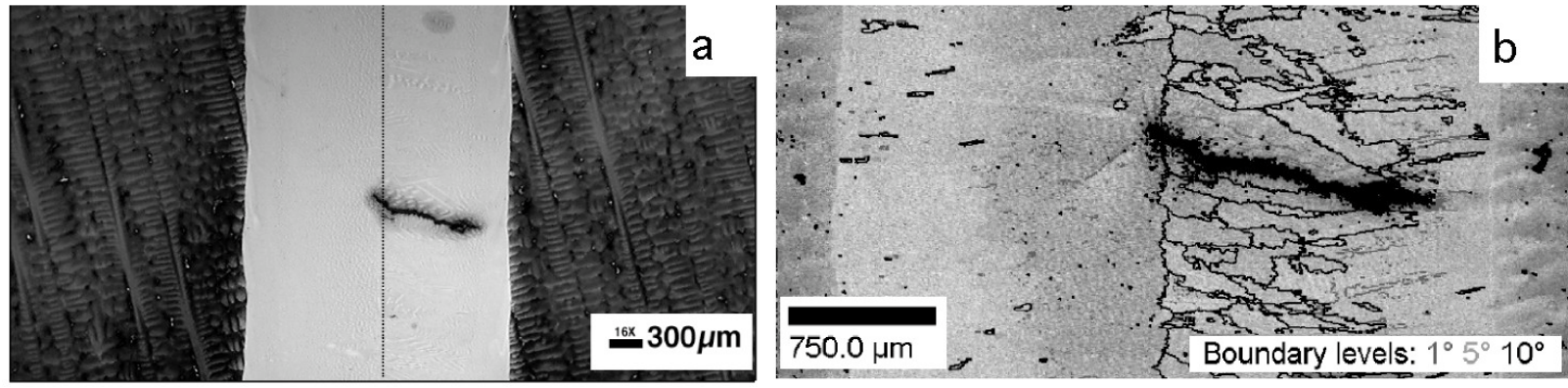

FIG. 1. (a) Optical micrograph of surface of laser welds made on single-crystal nickel base superalloy with welding speed of $12.7 \mathrm{~mm} / \mathrm{s},(b)$ Orientational imaging microscopy results showed the formation of high-angle grain boundaries on the right side of the weld.

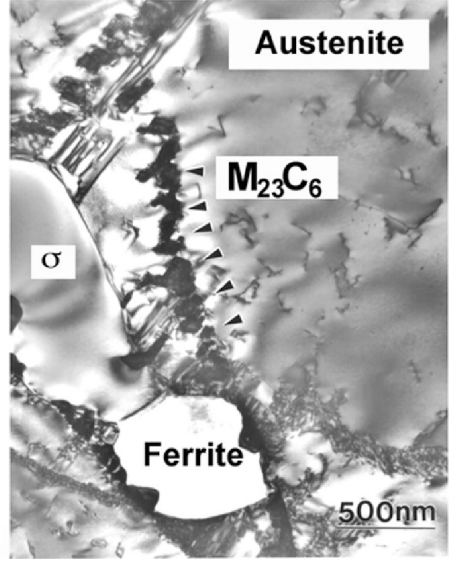

FIG. 2. Transmission electron micrograph showing the presence of many phases in a stainless steel weld after aging at $650^{\circ} \mathrm{C}$.

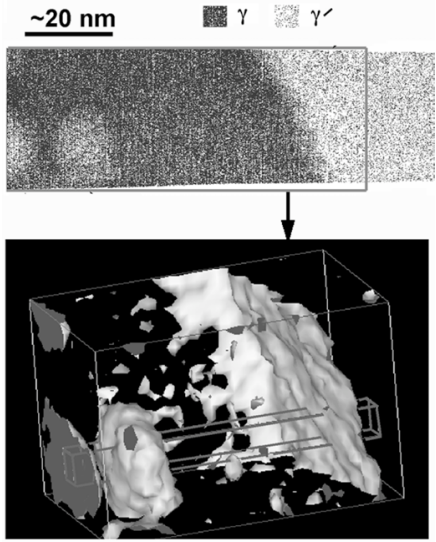

FIG. 3. Atom probe tomography shows the formation of secondary $\gamma^{\prime}$ phase within the $\gamma$ phase in a superalloy microstructure cooled at $1 \mathrm{Ks}^{-1}$ from $1300^{\circ} \mathrm{C}$. 